\title{
Physical properties of post-process fly ash from TWTP Krakow
}

\author{
Aneta Nowak-Michta ${ }^{1, *}$, and Brygida Kabat $^{1}$ \\ ${ }^{1}$ Chair of Building Materials Engineering, Cracow University of Technology, \\ Warszawska 24, Krakow 31-155, Poland
}

\begin{abstract}
Fly ashes from eco-incinerator according to the Art.7 of the Act of December 14, 2012 on waste are a hazardous waste. The growing amount of this type of waste generates a problem in terms of their management. They are a post-process waste, so their chemical composition is not constant and their quality is not very high. In addition, a high content of heavy metals with different concentrations may adversely affect the properties of these ashes. The physical properties of fly ashes originating from the TWTP in Krakow in the light of the requirements of PN-EN 4501 are analysed in the article. The aim of the paper is a preliminary assessment, based on the tests carried out on three random ashes, to check if there's a possibility of utilisation of this type of waste in concretes. The results of physical properties examination showed that they are coarse ashes with a several percent moisture content. They meet the requirements of PN-EN 450-1 in terms of the impact on the initial setting time and soundness. They cause an increase in the mortar's water demand. Their compression activity index after 28 days is $63-70 \%$, and after 90 days 56$67 \%$ and do not meet the standard requirements $(75 \%$ after 28 days and $85 \%$ after 90 days).
\end{abstract}

\section{Introduction}

An increasing amount of municipal solid waste generates a problem in terms of their management [1]. In order to reduce the amount of waste deposited, the process of thermal treatment of municipal waste is being disseminated. The third incinerator - The Thermal Waste Treatment Plant (TWTP) in Krakow - in the country was launched in December 2015. There are already 8 eco-incineration plants in Poland. Further investments are planned and by 202010 such establishments will be operating in Poland. It is estimated that this will allow for a thermal transformation of about $20 \%$ of waste per year [2-4].

As a result of the thermal transformation of municipal waste, in the waste-incineration plant in Krakow, post-process waste is produced in the form of:

- slag and bottom ash,

- boiler dust and fly ashes as well as solid residues from aftertreatment.

\footnotetext{
*Corresponding author: a nowak@pk.edu.pl
} 
All the listed residues represent $25 \%$ of the input stream. Slag and bottom ashes, which do not belong to hazardous waste, are used as a building material [4].

Boiler dusts and fly ashes as well as solid residues from the exhaust gas treatment are specified in the group 1901 and in accordance with the Act [5] on waste are a hazardous waste. Subjecting them to the stabilization and solidification process is aimed at converting them into inert other non-hazardous waste. This effect is achieved by mixing them with appropriate additives and hydraulic binders. Stabilization and solidification consists of two stages. The first stage (stabilization) is used to obtain an internal barrier that prevents the solubilization of soluble heavy metal compounds. At the second stage (solidification) an external barrier is created using various types of hydraulic binders (eg cement). Waste that is a product of this process meets the conditions that allow its storage [4]. The Waste Management Plan for the Małopolska Voivodship for the years 2016-2022 recommends reduction in the amount of landfilled waste which is to be managed. One of the ways of its management is its use in construction, e.g. as a substructure for roads, filling of mining remains or by adding fly ash to concretes [1].

The aim of the paper is to analyze physical properties of fly ashes originating from the Department of Thermal Waste Transformation in Krakow based on the requirements of PNEN 450-1 [6]. This work aims to determine, based on the tests carried out, whether it is possible to utilise of this type of waste in concretes.

\section{Experimental part}

\subsection{The purpose and scope of research}

The purpose of the research was to determine the impact of randomly selected fly ashes obtained from the thermal treatment of municipal waste in TWTP in Krakow on the physical properties of pastes and mortars made with their addition. The scope of research included physical properties required in accordance with PN-EN 450-1: 2012 [6]:

- fineness,

- initial and final setting time,

- soundness,

- water demand,

- activity index, and also:

- sieve analysis,

- humidity.

\subsection{Testing of fly ashes}

Three different fly ashes from the thermal treatment of municipal waste in the TWTP in Krakow were obtained from a company "EKO SMOK" dealing with the collection of waste from public institutions. Ashes differ in the content of heavy metals in the chemical composition. The first of them (FA1) is a waste with a code 190107 (fly ash from a flue gas cleaning system), the second one (FA2) has a code 190113 (fly ashes containing dangerous substances), while the last one (FA3) is a mixture of the two previous ashes. All of these ashes are a hazardous waste due to the content of heavy metals: barium, cadmium, chromium, copper, nickel, mercury, lead and others contained in the Annex 4 of the Act of 14 December 2012 on waste [5].

The contents of heavy metals in the ashes and a detailed description of the test procedures are given in [7]. 


\subsubsection{Fineness}

Fineness of ashes was determined in the process of wet sieving according to PN-EN 4512:2017 [8].

\subsubsection{Sieve analysis}

Sieve analysis of fly ashes was carried out according to PN-EN 933-1:2012 [9].

\subsubsection{Humidity}

The humidity of the ashes was determined by drying to a constant mass at a temperature of $105^{\circ} \mathrm{C}$

\subsection{Testing of pastes}

Pastes with a standard consistency were prepared in accordance with PN-EN 196-3: 2006 [10]. Four pastes were made, one using only cement and three being a mixture of $25 \%$ of ash and $75 \%$ of cement. Dry ashes, sieved through a $2 \mathrm{~mm}$ sieve, were used for the pastes. The amounts of water needed to obtain the pastes with a standard consistency are given in Table 1.

Table 1. The amounts of water needed to obtain the pastes with a standard consistency.

\begin{tabular}{|c|c|c|c|}
\hline & Cement & Fly ash & Water \\
\hline & \multicolumn{3}{|c|}{$(\mathrm{g})$} \\
\hline C & 500 & - & 147 \\
\hline FA1 & 375 & 125 & 173 \\
\hline FA2 & 375 & 125 & 180 \\
\hline FA3 & 375 & 125 & 140 \\
\hline
\end{tabular}

\subsubsection{Initial and final setting time}

Initial and final setting time was marked on pastes with a standard consistency for cement and for three tested ashes FA1, FA2 and FA3 according to PN-EN 196-3:2006 [10].

\subsubsection{Soundness}

The soundness was determined on pastes with a standard consistency for cement and for three ashes FA1, FA2 and FA3 according to PN-EN 196-3: 2006 [10].

\subsection{Testing of mortars}

Four standard mortars were prepared according to PN-EN 196-1: 2006 [11]. One of the comparative cement itself and three, in which $30 \%$ of cement was successively replaced with FA1, FA2 and FA3. Dry ashes, sieved through a $2 \mathrm{~mm}$ sieve, were used for the mortars. 


\subsubsection{Water demand}

Water demand of fly ashes FA1, FA2 i FA3 were marked in accordance with Annex B of the standard PN-EN 450-1:2012 [6]. The test consisted of determining the amount of water with which the spreading of the mortar with a $30 \%$ ash content in the binder is equal to \pm $10 \mathrm{~mm}$ spreading of the control (cement) mortar. The water demand of ash is calculated by comparing the amount of water in the mortar with $30 \%$ ash content in the binder with the amount of water in the control mortar.

\subsubsection{Activity index}

In order to determine the activity indexes of ashes FA1, FA2 and FA3 four sets of bars with dimensions of $40 \times 40 \times 160 \mathrm{~mm}$ were prepared for each of the ashes and one for the control mortar. Activity indexes were determined during flexing and compressing after 7, 14, 28 and 90 days according to PN-EN 450-1: 2012 [6]. In order to determine the indexes of flexural and compressive activity, the flexural strength and compressive strength of the mortar with the addition of ashes should be compared with the strength of the control mortar.

\section{Research results and their analysis}

\subsection{Humidity of fly ashes}

Humidity contents in FA1 and FA2 were at a similar level of around 18\%. Fly ash FA3 has the least humidity $(4.3 \%)$. The ashes for further tests were dried to a constant weight at $105^{\circ} \mathrm{C}$

\subsection{Fly Ashes sieving analysis}

Fig. 1 contains the curves of ash graining. Ashes FA1 and FA2 are characterized by a similar grain size, whereas FA3 is finer. For further tests, ashes with fractions up to $2 \mathrm{~mm}$ were used.

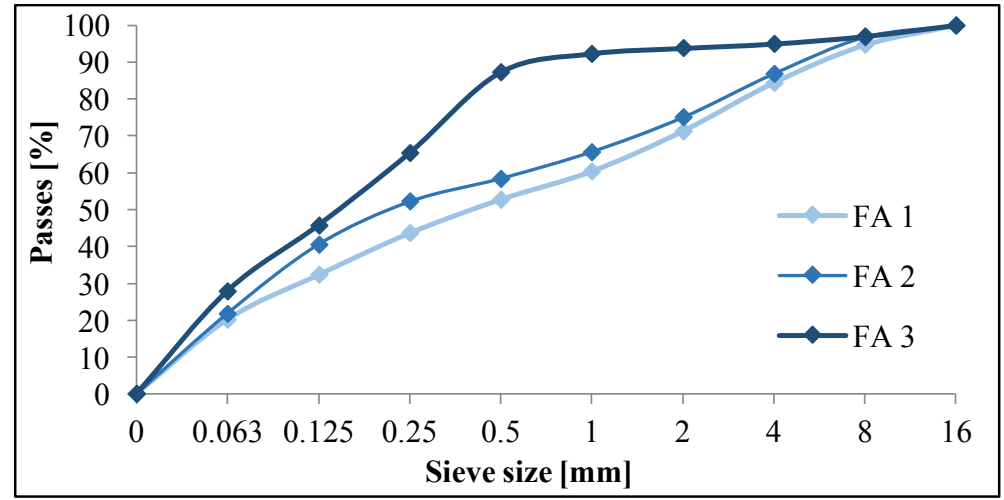

Fig. 1. Fly ashes grain curves. 


\subsection{Flexural strength of mortars}

Fig. 2 presents graphs of flexural strength of mortars: the cement one and three with the addition of all ashes. The flexural strength of cement mortar was increasing in a standard way over a period of time. The mortars with the addition of all three ashes after 7 days gained $67-80 \%$ of the 90 day strength, which was about $8 \mathrm{MPa}$. There was no increase in strength between 7 and 28 days. The activities of all three ashes during flexing are similar. After 7 days the activity was the highest and fluctuated for individual ashes from $69-84 \%$, while at later dates it fluctuated around $60 \%$.

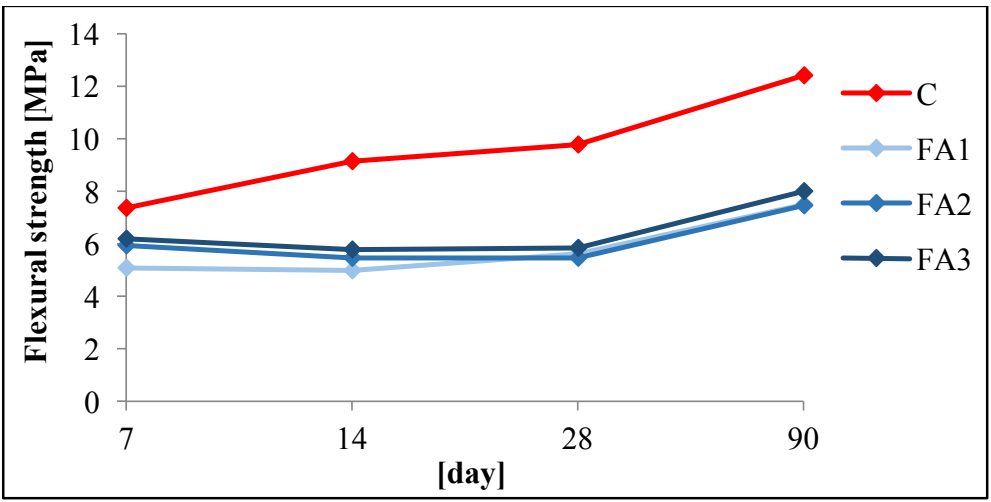

Fig. 2. Flexural strength of mortars.

\subsection{Compressive strength of mortars}

Fig. 3 presents the graphs of compressive strength of mortars: the cement one and three with the addition of all ashes. The kinetics of the compressive strength of cement mortar was a standard one. Mortars with the addition of all three ashes had similar compressive strengths and kinetics of their growth. After 7 days, the compressive strength of mortars with the addition of ashes was about 22MPa, after 14 days 28-30MPa, after 28 days $34-38 \mathrm{MPa}$, and after 90 days $40-46 \mathrm{MPa}$. Thus, the activity of ashes after 7 days was $45 \%$, and at later stages it fluctuated around $60 \%$.

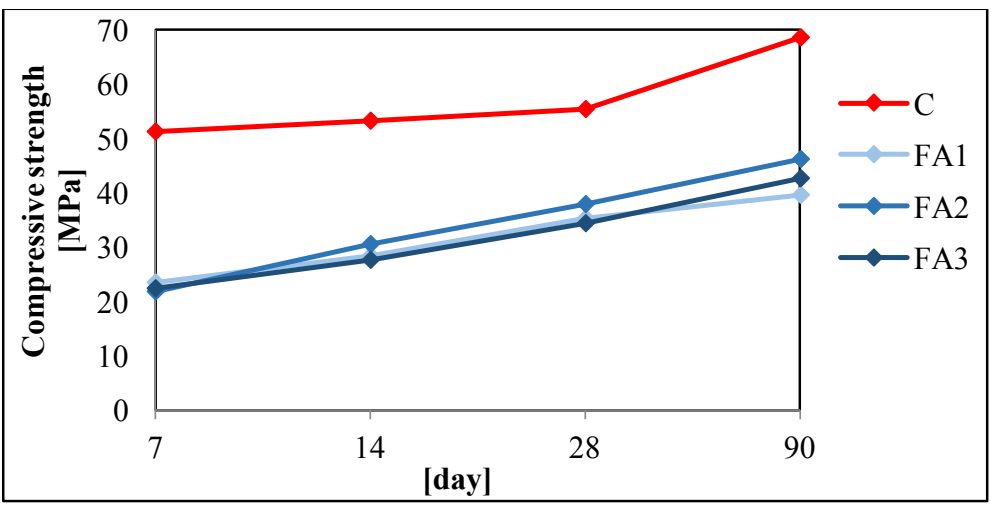

Fig. 3. Compressive strength of mortars. 


\subsection{Physical properties of fly ashes consistent with PN-EN 450-1:2012}

Table 2 contains the requirements of PN-EN 450-1 [6] regarding physical properties for fly ashes, which can be used as an addition to concretes as well as the obtained results for ashes FA1, FA2 and FA3 from the incineration of municipal waste in TWTP in Krakow and their assessment in the light of the standard requirements. Fineness of the ash FA2 fulfilled the requirement [6] for the $\mathrm{N}$ category. All ashes met the requirements regarding the effect on the initial setting time as well as on the soundness. Ashes FA1 and FA2 had significantly shorter initial setting times than cement. Moreover, FA2 ash did not meet the requirements of PN-EN 197 [12] in terms of the minimum time for the cement class 42.5 which is 60 minutes. The requirements regarding the influence on the water demand and the compression activity index were not met by any of the tested ashes. The increase in water demand for FA1 and FA3 ashes was $18 \%$, while for FA3 ash - 36\%. Activity indexes neither after 28 nor 90 days reached the required levels. After 28 days, they ranged from $62.9-69.5 \%$ (required at least $75 \%$ ), and after 90 days from 56.4 to $66.7 \%$ (required at least $85 \%)$.

Table 2. Physical properties of ashes and their assessment according to PN-EN 450-1 [6].

\begin{tabular}{|c|c|c|c|c|}
\hline Feature & $\begin{array}{c}\text { Requirements of } \\
\text { PN-EN 450-1:2012 } \\
\end{array}$ & \multicolumn{2}{|c|}{ Tests results } & Assesment \\
\hline \multirow{3}{*}{ Fineness [\%] } & \multirow{3}{*}{$\begin{array}{l}\text { Cathegory } \mathrm{S}: \leq 12 \\
\text { Cathegory } \mathrm{N}: \leq 40\end{array}$} & \multicolumn{2}{|c|}{ FA1: 42.2} & does not meet \\
\hline & & \multicolumn{2}{|c|}{ FA2: 29.6} & Cathegory N \\
\hline & & \multicolumn{2}{|c|}{ FA $: 67.2$} & does not meet \\
\hline \multirow{4}{*}{$\begin{array}{l}\text { Initial setting time } \\
{[\mathrm{min}]}\end{array}$} & \multirow{4}{*}{$\begin{array}{l}\text { The initial setting } \\
\text { time not more than } \\
\text { twice as long as the } \\
\text { start of the leaven } \\
\text { paste with cement } \\
\text { alone }\end{array}$} & \multicolumn{2}{|c|}{ C: 158} & - \\
\hline & & \multicolumn{2}{|c|}{ FA1: 70} & meet \\
\hline & & \multicolumn{2}{|c|}{ FA2: 28} & does not meet [13] \\
\hline & & \multicolumn{2}{|c|}{ FA3: 198} & meet \\
\hline \multirow{4}{*}{$\begin{array}{l}\text { Final setting time } \\
{[\text { min] }}\end{array}$} & \multirow{4}{*}{ no requirements } & \multicolumn{2}{|c|}{ C: 361} & - \\
\hline & & \multicolumn{2}{|c|}{ FA 1: 233} & - \\
\hline & & \multicolumn{2}{|c|}{ FA 2: 193} & - \\
\hline & & \multicolumn{2}{|c|}{ FA $3: 325$} & - \\
\hline \multirow{4}{*}{ Soundness $[\mathrm{mm}]$} & \multirow{4}{*}{$\leq 10 \mathrm{~mm}$} & \multicolumn{2}{|c|}{ C: 0.5} & meet \\
\hline & & \multicolumn{2}{|c|}{ FA 1: 2.4} & meet \\
\hline & & \multicolumn{2}{|c|}{ FA 2: 0.2} & meet \\
\hline & & \multicolumn{2}{|c|}{ FA 3: 0.8} & meet \\
\hline \multirow{3}{*}{ Water demand [\%] } & \multirow{3}{*}{$\begin{array}{l}\leq 95 \% \text { water demand } \\
\text { for mortar from } \\
\text { cement alone CEM I }\end{array}$} & \multicolumn{2}{|c|}{ FA $1: 118$} & does not meet \\
\hline & & \multicolumn{2}{|c|}{ FA 2: 136} & does not meet \\
\hline & & \multicolumn{2}{|c|}{ FA 3: 118} & does not meet \\
\hline \multirow{4}{*}{$\begin{array}{l}\text { Flexural activity } \\
\text { index }[\%]\end{array}$} & \multirow{4}{*}{ no requirements } & FA1 & $\begin{array}{l}28: 57.6 \\
90: 60.4\end{array}$ & - \\
\hline & & FA 2 & $\begin{array}{l}28: 56.0 \\
90 \cdot 60.0\end{array}$ & - \\
\hline & & 543 & $28: 60.0$ & 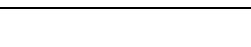 \\
\hline & & FA 3 & $90: 64.3$ & - \\
\hline
\end{tabular}




\begin{tabular}{|c|c|c|c|c|}
\hline \multirow{5}{*}{$\begin{array}{c}\text { Compressive activity } \\
\text { index }[\%]\end{array}$} & \multirow{5}{*}{$\begin{array}{l}\text { After } 28 \text { days: } \geq 75 \% \\
\text { After } 90 \text { days: } \geq 85 \%\end{array}$} & FA 1 & $\begin{array}{l}28: 64.6 \\
90: 56.4\end{array}$ & does not meet \\
\hline & & \multirow{2}{*}{ FA 2} & $28: 69.5$ & \multirow{2}{*}{ does not meet } \\
\hline & & & $90: 66.7$ & \\
\hline & & \multirow{2}{*}{ FA 3} & 28: 62.9 & \multirow{2}{*}{ does not meet } \\
\hline & & & $90: 61.9$ & \\
\hline
\end{tabular}

\section{Conclusions}

Fly ashes from the eco-incineration plant are a post-process waste and because of that their chemical composition is not constant and in terms of properties they do not meet all the standard requirements for ashes used as an addition to concretes [13]. Moreover, a high content of heavy metals with different concentrations may adversely affect the properties of these ashes. However, these ashes also show positive features, i.e.: such as soundness, setting time and some degree of pozzolanic activity, which open up the chances of utilizing this type of waste in concretes. In order to effectively assess the possibility of using these ashes in concretes, their chemical analysis is required, especially regarding the content of heavy metals and unwanted soluble compounds as well as the possibility of their immobilization [14].

\section{References}

1. Waste Management Plan for the Małopolska Region for 2016-2022 (Kraków, 2016) in Polish

2. G. Wielgosiński, O. Namiecińska, Nowa Energia 2 (2016)

3. R. Ziaja, Ogólnopolska Konferencja Młodych Energetyków, 5-16 (2016) in Polish

4. https://khk.krakow.pl/en/eco-incinerator/project/ (June 2017)

5. The Act of 14 December 2012 on waste (Journal of Laws, 2013 item 21)

6. PN-EN 450-1 (2012)

7. B. Kabat, Preliminary assessment of municipal waste incineration ash disposal possibilities in concrete production, (Cracow University of Technology, 2017) in Polish

8. PN-EN 451-2 (2017)

9. PN-EN 933-1 (2012)

10. PN-EN 196-3 (2016)

11. PN-EN 196-1 (2006)

12. PN-EN 197-1 (2012)

13. PN-EN 206+A1 (2016)

14. T. Stryszewska, M. Dudek, 8th Scientific-Technical Conference on Material Problems in Civil Engineering MATBUD'2018 Cracow (2018) 
